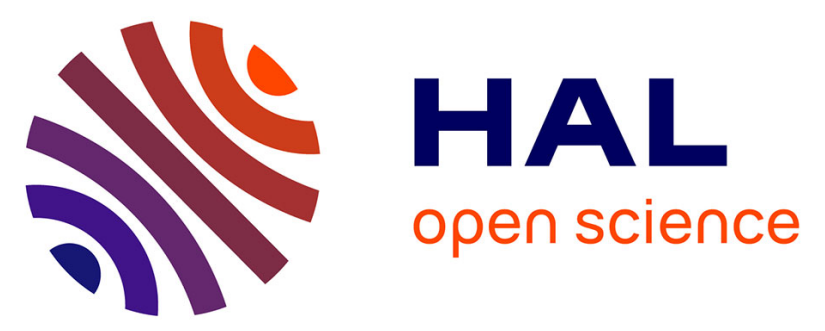

\title{
Comparative biomechanical study of five systems for fixation of the coracoid transfer during the Latarjet procedure for treatment of anterior recurrent shoulder instability
}

Valentin Massin, Damien Lami, Matthieu Ollivier, Martine Pithioux, Jean-Noël Argenson

\section{To cite this version:}

Valentin Massin, Damien Lami, Matthieu Ollivier, Martine Pithioux, Jean-Noël Argenson. Comparative biomechanical study of five systems for fixation of the coracoid transfer during the Latarjet procedure for treatment of anterior recurrent shoulder instability. International Orthopaedics, 2020, 44 (9), pp.1767-1772. 10.1007/s00264-020-04565-2 . hal-03176992

\section{HAL Id: hal-03176992 \\ https://hal.science/hal-03176992}

Submitted on 19 Apr 2021

HAL is a multi-disciplinary open access archive for the deposit and dissemination of scientific research documents, whether they are published or not. The documents may come from teaching and research institutions in France or abroad, or from public or private research centers.
L'archive ouverte pluridisciplinaire HAL, est destinée au dépôt et à la diffusion de documents scientifiques de niveau recherche, publiés ou non, émanant des établissements d'enseignement et de recherche français ou étrangers, des laboratoires publics ou privés. 


\section{International Orthopaedics}

\section{COMPARATIVE BIOMECHANICAL STUDY OF FIVE SYSTEMS FOR FIXATION OF THE CORACOID TRANSFER DURING THE LATARJET PROCEDURE FOR TREATMENT OF ANTERIOR RECCURENT SHOULDER INSTABILITY --Manuscript Draft--}

Manuscript Number:

Full Title:

\section{Article Type:}

Funding Information:

Corresponding Author:
Abstract:

INOR-D-19-02307R2

COMPARATIVE BIOMECHANICAL STUDY OF FIVE SYSTEMS FOR FIXATION OF THE CORACOID TRANSFER DURING THE LATARJET PROCEDURE FOR TREATMENT OF ANTERIOR RECCURENT SHOULDER INSTABILITY

Original Paper

ABSTRACT

Introduction

This work compares the biomechanical resistance of five modes of fixation coracoid bone-block fixation during Latarjet open-air or arthroscopic procedures. The hypothesis is that these systems are equivalent.

Material and Methods

Latarjet procedures were performed on cadavers, then the samples were subjected to an increasing tension until the fixation failed. Five systems were tested: 2 malleolar screws, 1 screw with washer, $23.5 \mathrm{~mm}$ self-compressive screws, $14 \mathrm{~mm}$ selfcompressive screw associated with $13 \mathrm{~mm}$ self-compressive screw, and endobutton. The main judgement criterion was the strength necessary for the failure of the fixation. The secondary criterion was the stiffness of the assembly.

Results

The single malleolar screw fixing has a lower breaking thresehold than other fixings. There is no difference in strength concerning the other systems. The average strength is greater than the stresses of a shoulder during daily life activities. There is no difference regarding the secondary criterion.

Conclusion

The use of a single screw is insufficient, but the other systems seems reliable. The use of small diameter self-compressive cannulated screws can provide a better result. This biomechanical work must be validated in clinical studies.

Valentin MASSIN

Aix-Marseille Universite

FRANCE

\section{Corresponding Author Secondary}

Information:

Corresponding Author's Institution:

Aix-Marseille Universite

Corresponding Author's Secondary Institution:

First Author:

Valentin MASSIN

First Author Secondary Information:

Order of Authors:

Valentin MASSIN

Damien Lami, MD

Matthieu Ollivier, MD, PhD

Martine Pithioux, PhD

Jean-Noël Argenson, MD, PhD

Order of Authors Secondary Information:

Author Comments:

Thank you for reviewing.

Response to Reviewers:

Dear reviewers, 
Thank you for reviewing this work.

As you ask me, I include references you provided in the manuscript.

I also made schema to explain fixation devices (Figure 2).

The manuscript has been check by English native person to ensure grammatical reliability.

As you mentioned, there is already papers comparing different fixation devices, but there is no one comparing this self-compressive screws with "new" devices as endobutton and two diameters self-compressive screws and the gold standard malleolar screws. Moreover, there is no paper about testing both traction of the conjoint tendon and pull-out of the humeral head in the same test, as we performed using a traction machine with the scapula in the following position. 


\title{
COMPARATIVE BIOMECHANICAL STUDY OF FIVE SYSTEMS FOR FIXATION OF THE CORACOID TRANSFER DURING THE LATARJET PROCEDURE FOR TREATMENT OF ANTERIOR RECCURENT SHOULDER INSTABILITY
}

\author{
Valentin MASSIN ${ }^{1}$ \\ Damien LAMI, MD ${ }^{1}$ \\ Matthieu OLLIVIER, MD, $\mathrm{PhD}^{1}$ \\ Martine PITHIOUX, $\mathrm{PhD}^{2,3}$ \\ Jean-Noël ARGENSON, MD, $\mathrm{PhD}^{1}$
}

${ }^{1}$ Department of Orthopedics and Traumatology

Sainte-Marguerite Hospital, Assistance Publique - Hôpitaux de Marseille

Marseille, France

\footnotetext{
${ }^{2}$ Aix Marseille University, CNRS, ISM

Marseille, France

${ }^{3}$ Aix Marseille University, APHM, CNRS, ISM

Sainte-Marguerite Hospital, Department of Orthopedics and Traumatology

Marseille, France
}

Conflict of interest: On behalf of all authors, the corresponding author states that there is no conflict of interes

Corresponding author: Valentin MASSIN (valentinmassin@free.fr) 
COMPARATIVE BIOMECHANICAL STUDY OF FIVE SYSTEMS FOR FIXATION OF THE CORACOID TRANSFER DURING THE LATARJET PROCEDURE FOR TREATMENT OF ANTERIOR RECCURENT SHOULDER INSTABILITY 


\section{ABSTRACT}

\section{Purpose}

This work compares the biomechanical resistance of five modes of fixation coracoid bone-block fixation during Latarjet open-air or arthroscopic procedures. The hypothesis is that these systems are equivalent.

\section{Methods}

Latarjet procedures were performed on cadavers, then the samples were subjected to an increasing tension until the fixation failed. Five systems were tested: 2 malleolar screws, 1 screw with washer, $23.5 \mathrm{~mm}$ self-compressive screws, $14 \mathrm{~mm}$ self-compressive screw associated with $13 \mathrm{~mm}$ self-compressive screw, and endobutton. The main judgement criterion was the strength necessary for the failure of the fixation. The secondary criterion was the stiffness of the assembly.

\section{Results}

The single malleolar screw fixing has a lower breaking thresehold than other fixings. There is no difference in strength concerning the other systems. The average strength is greater than the stresses of a shoulder during daily life activities. There is no difference regarding the secondary criterion.

\section{Conclusion}

The use of a single screw is insufficient, but the other systems seems reliable. The use of small diameter self-compressive cannulated screws can provide a better result. This biomechanical work must be validated in clinical studies.

Keywords : Latarjet procedure, coracoid bone-block, glenohumeral instability, glenohumeral stabilization, fixation system, graft healing 


\section{I - INTRODUCTION}

Glenohumeral stabilization by coracoid bone-block was described in 1954 by Latarjet[1]. The procedure consists, by a delto-pectoral approach, in transposing the horizontal portion of the coracoid process to the lying position at the anterior-inferior edge of the glenoid, through an incision in the tendon of the subscapular.

Stabilization is obtained by a stop effect related to the increase of the inferior-internal rim of the glenoid, associated with a sling effect of the coraco-biceps tendon when placing the upper limb in anterior elevation. Patte[2] and Walch[3] proposed improvements to the original technique, doing a capsuloplasty on the coracoacromial ligament. Coracoid bone grafting can restore the glenoid rim defect[4], and this triple locking technique remains the gold standard for the treatment of anterior glenohumeral instability $[5,6]$.

The results are effective with a recurrence in 1 to $7 \%$ of cases and a low number of complications[7].

Bone-block fixation is essential because poor bone contact is responsible for nonunion[8] [Fig 1]. In the Latarjet-Patte-Walch procedure, the coracoid process is fixed by two 4.5mm partial threaded cancellous AO malleolar screws.

Failure and re-intervention can occur in case of non-union, lysis of the bone-block or secondary displacement $[9,10]$, and the length of the screws can cause neurological damage[11].

Other fixing methods were later described to overcome these pitfalls: use of a single screw, optimization of the screw support using a washer or miniplate, use of screws with a smaller diameter, full threaded or cannulated screw as Saragaglia's mini-invasive technique[12].

Recently, Lafosse[13] described arthroscopic procedure using two screws, while Boileau[14], described cortical button fixation. Arthroscopic procedure seems to be as reliable as open procedure regarding to the positioning of the graft[15], and Kordasiewicz showed a very high graft healing rate using two cannulated screws with washers[16]. 
Several studies have already compared the methods of fixing the block, whether on biomechanical models or on cadaveric models[17-19]. The resistance of endobuttons has also been studied compared to malleolar screws[14, 20, 21]. Previous works have shown that bicortical fastening systems are more resistant than the use of unicortical screws[18, 22].

The use of self-compressive screws such as Herbert seems to us be an interesting option to allow good contact between the bone-block and the glenoid and to promote boneunion[23]. However, they have not been studied biomechanically in this application.

Given the diversity of fastening systems on the market, we wanted to compare their effectiveness under physiological conditions. The purpose of this study is to explore the strength of these systems, in order to choose the one that offers satisfactory strength, while allowing optimal contact between the bone surfaces, minimum drilling to avoid weakening the bone-block and offering solutions for precise placement of the block. Null hypothesis was that all these fixation systems are bio-equivalent on resistance to tensile strength.

The main judgement criterion was the maximum strength developed to achieve system failure.

The secondary judgement criterion was the stiffness of the assembly, calculated from the force/displacement curve of each test.

\section{II - MATERIAL AND METHODS}

Five fixation devices of coracoid bone-block were tested during a cadaveric biomechanical study : 2 4.5mm malleolar solid screws (Synthes, West Chester, USA), 1 $4.5 \mathrm{~mm}$ malleolar solid screw with washer (Synthes, West Chester, USA), 1 endobutton (Implanet, Martillac, France), $14 \mathrm{~mm}$ self-compressive cannulated screw $+13 \mathrm{~mm}$ selfcompressive cannulated screw (Newclip Technics, Haute-Goulaine, France), 2 3.5mm self-compressive cannulated screws (Newclip Technics, Haute-Goulaine, France) [Fig 2]. 
For each of the 5 fixing modes, three laboratory tests were carried out. The shoulders were randomized, with a matched allocation so that two joints from the same cadaver would not be tested with the same device.

Cadaver with a surgical or shoulder trauma history were excluded.

For each shoulder, a Latarjet procedure was performed, then the scapula was included in a resin in a testing position allowing the force vector to simulate both the humeral head pressure and coraco-biceps traction, as described in previous work[17, 21] [Fig 3].

All screws were bicortical. The tightening was done in real conditions: with two fingers, using the dedicated screwdriver, until a tension considered sufficient by the operator was reached. Traction was increasingly performed at a rate of $10 \mathrm{~mm} . \mathrm{min}^{-1}$ with a traction machine equipped with a $1000 \mathrm{~N}$ sensor, with an accuracy of $+/-5^{*} 10^{-3} \mathrm{~N}$ (E5566A, Instron, Norwood, USA). The data obtained were processed using BlueHill 3 software (ITW, Norwood, USA).

A failure of the assembly was noted in the event of bone-block fracture, fixing material failure, bone-block displacement by more than $3 \mathrm{~mm}$ from its initial position [Fig 4].

For each fixing method, mean strength and stiffness values of the 3 tests were compared to the mean of all other fixing modes using Mann-Whitney tests. Statistical tests were carried out using P-Value, graphical interface of R software (The R Foundation, Vienna, Austria).

\section{III - RESULTS}

A strength/displacement curve was obtained from each test [Fig. 5], and derivated function at the failure point was used to calculate stiffness.

Failure mode was different according to the type of fixing: single screw generally induced a displacement of the block around the screw then a tearing off, while fixing with large diameter screws $(4.5 \mathrm{~mm})$ induces a block's fracture or a cut-out of the screw.

For all the tests performed, the mean failure threshold was 193N (SD 112N). 
The strength of failure for each fixing method using 2 screws or 1 endobutton is equivalent, without any significative difference. At the opposite, testing using 1 malleolar screw and washer showed a significative weaker fixation strength, with a mean strength of $86 \mathrm{~N}(\mathrm{SD} 27,1 \mathrm{~N}, \mathrm{p}<0.01)$ [Table 1].

Mean stiffness of all systems was $14,6 \mathrm{~N} \cdot \mathrm{mm}^{-1}$ (SD 4,77N.mm ${ }^{-1}$ ). Stiffness of the “endobutton group" was lower $11,6 \mathrm{~N} \cdot \mathrm{mm}^{-1}\left(\mathrm{SD} 1,44 \mathrm{~N} \cdot \mathrm{mm}^{-1}\right)$, in a non-significant way. There was no difference on the secondary judgement criterion according to the others types of fixation [Table 1].

\section{IV - DISCUSSION}

Latarjet-Patte-Walch's procedure has become common because of its good clinical results[7]. Over successive developments and in particular since arthroscopic improvement, several fixing methods have been described and tested[14, 17, 21, 24, 25]. In order to optimize the clinical result, the positioning of the block is essential[26]. However, complications during fixation are frequent: according to Willemot, graft nonunion is responsible of most revision cases[9]. The parameters influencing bone consolidation are numerous[27] but one of the most important is the contact between the two bone pieces. Claes showed less healing when the gap between the two bone pieces is greater than $2 \mathrm{~mm}[28]$, that's why a $3 \mathrm{~mm}$ displacement was considered as a failure.

Several types of screws have been marketed to solve these issues, by offering k-wires sighting instruments and self-compressive screws.

The aim of this study was to test the biomechanical resistance of these systems and compare them to the gold standard of open-air and arthroscopic Latarjet.

This study has several limitations: because it is a cadaveric work, the constraints applied to the model may differ from reality. Nevertheless, we tried to reproduce both the coracobiceps' traction force and the humeral head's pressure force. Bone quality can be changing: most of anatomical subjects used come from elderly patients, and conservation care can alter bone quality. The shoulders were randomized in the study groups to avoid 
a bias related to very porotic bone, but Latarjet procedure is proper to young people: it is likely that bone quality supposed to be better, so failure thresholds in real conditions may be higher.

This work is original since it compares five different bone-block' fixation, using a standardized model. The gold standard is compared to commonly used and recently developed fasterners. The coraco-biceps' tensile force is taken into account, which is generally neglected in this type of study[17, 22], despite its stabilizing role[29].

The methods of attaching the coracoid bone-block, using two bicortical screws or an endobutton therefore seem equivalent. While failures way vary, means are comparable which shows a homogeneity of testing. Standard deviations are relatively large, due to a low number of samples per group and likely sampling fluctuations, which are common in cadaveric studies. However, there is quite a homogeneity in order of magnitude, which are comparable to those described in the literature.

On the other hand, fixing with a single screw shows a lower failure threshold. It seems insufficient, even with bicortical screwing and distributing stresses along a washer[25]. The stiffness of the assemblies is also similar: these fixing methods suffer little distortion and failure mostly result as a tearing off of the bone/screw complex, or a bone-block's fracture on the screw holes.

The mean strength values of groups using endobutton or two screws are higher than the strength applied to a shoulder in daily life activities[30]. Concerning the "screw + washer" group, the rupture may occur too early, especially since the coraco-biceps tension has not been measured in vivo in the literature and remains unknown to date.

The use of a single screw is intended to reduce the risk of a small block fracture. Nevertheless, due to its reduced stability, the choice of this system seems to us to be abandoned. It may be more appropriate to turn to smaller diameter screws than to a single one.

The use of self-compressive Herbert type screws ensures a good biomechanical resistance. As these screws are cannulated, they also provide precise positioning through use of k-wires. Alvi also showed biomechanical equivalence between cannulated and solid screws[17]. 
We have shown here a biomechanical equivalence in strength and stiffness between solid screws with a 4.5 diameter and cannulated screws with 3.5 diameter. This allow the drilling of holes with a smaller diameter, which favors holding in the cancellous bone[31]. Finally, as Gender previously noted, endobuttons seems to fully meet the requirements for this procedure and make it possible to safely replace use of screws[20]. The stiffness is slightly less, in a non-significant way, than the other groups. This shows the relative elasticity of this kind of assembly, as opposed to solid metal screws that support few distortion, and even if single-point fixations have a tendency to rotate around this pivot, it does not seem to impact the strength of failure.

This work should be completed by clinical studies, as radiological failures such nonunions or bone-block lyses have not always led to recurrence of instability or surgical recovery[10].

\section{V - CONCLUSION}

The methods of coracoid bone-block fixation tested in this study appear to be biomechanically comparable, except the use of a single screw that shows a lower failure threshold. Systems based on two bicortical screws or an endobutton accept higher stresses than those to which the joint is usually subjected. We can consider them to be reliable, as tensile tests are reproductible. Their stiffness is comparable, which implies that these devices may don't deform under the effect of the stresses they undergo.

The use of a single screw should be abandoned at the risk of insufficient fixation including secondary displacement or increased pseudarthrosis.

The use of a small diameter screws can reduce the risk of fracture, and the use of cannulated self-compressive screws can increase the contact with the glenoid edge to maximize healing, while allowing accurate placement of the bone-block using specific instruments. Herbert $3.5 \mathrm{~mm}$ screws can solve all these problems. However, it is essential to clinically assess our biomechanical observations and further studies must be performed. 


\section{VI - REFERENCES}

1. Latarjet M (1954) [Treatment of recurrent dislocation of the shoulder]. Lyon Chir 49:994-997

2. Patte D, Bernageau J, Rodineau J, Gardes JC (1980) [Unstable painful shoulders (author's transl)]. Rev Chir Orthop Reparatrice Appar Mot 66:157-165

3. Bradley Edwards T, Walch G (2002) The latarjet procedure for recurrent anterior shoulder instability: Rationale and technique. Operative Techniques in Sports Medicine 10:25-32. https://doi.org/10.1053/otsm.2002.28776

4. Paladini P, Singla R, Merolla G, Porcellini G (2016) Latarjet procedure: is the coracoid enough to restore the glenoid surface? Int Orthop 40:1675-1681. https://doi.org/10.1007/s00264-015-3093-z

5. Boileau P, Mercier N, Old J (2010) Arthroscopic Bankart-Bristow-Latarjet (2B3) Procedure: How to Do It and Tricks To Make it Easier and Safe. Orthop Clin North Am 41:381-392. https://doi.org/10.1016/j.ocl.2010.03.005

6. De Carli A, Vadalà A, Proietti L, et al (2019) Latarjet procedure versus open capsuloplasty in traumatic anterior shoulder dislocation: long-term clinical and functional results. Int Orthop 43:237-242. https://doi.org/10.1007/s00264-0184195-1

7. Mizuno N, Denard PJ, Raiss P, et al (2014) Long-term results of the Latarjet procedure for anterior instability of the shoulder. J Shoulder Elbow Surg 23:16911699. https://doi.org/10.1016/j.jse.2014.02.015

8. Schell H, Epari DR, Kassi JP, et al (2005) The course of bone healing is influenced by the initial shear fixation stability. J Orthop Res 23:1022-1028. https://doi.org/10.1016/j.orthres.2005.03.005

9. Willemot L, De Boey S, Van Tongel A, et al (2019) Analysis of failures after the Bristow-Latarjet procedure for recurrent shoulder instability. Int Orthop 43:18991907. https://doi.org/10.1007/s00264-018-4105-6

10. Griesser MJ, Harris JD, McCoy BW, et al (2013) Complications and re-operations after Bristow-Latarjet shoulder stabilization: a systematic review. J Shoulder Elbow Surg 22:286-292. https://doi.org/10.1016/j.jse.2012.09.009

11. Lädermann A, Denard PJ, Burkhart SS (2012) Injury of the suprascapular nerve during latarjet procedure: an anatomic study. Arthroscopy 28:316-321. https://doi.org/10.1016/j.arthro.2011.08.307

12. Lateur G, Pailhe R, Refaie R, et al (2018) Results of the Latarjet coracoid bone block procedure performed by mini invasive approach. Int Orthop 42:2397-2402. https://doi.org/10.1007/s00264-018-3914-y 
13. Lafosse L, Lejeune E, Bouchard A, et al (2007) The arthroscopic Latarjet procedure for the treatment of anterior shoulder instability. Arthroscopy 23:1242.e1-5. https://doi.org/10.1016/j.arthro.2007.06.008

14. Boileau P, Gendre P, Baba M, et al (2016) A guided surgical approach and novel fixation method for arthroscopic Latarjet. J Shoulder Elbow Surg 25:78-89. https://doi.org/10.1016/j.jse.2015.06.001

15. Kordasiewicz B, Małachowski K, Kicinski M, et al (2017) Comparative study of open and arthroscopic coracoid transfer for shoulder anterior instability (Latarjet)clinical results at short term follow-up. Int Orthop 41:1023-1033. https://doi.org/10.1007/s00264-016-3372-3

16. Kordasiewicz B, Kicinski M, Małachowski K, et al (2018) Comparative study of open and arthroscopic coracoid transfer for shoulder anterior instability (Latarjet)computed tomography evaluation at a short term follow-up. Part II. Int Orthop 42:1119-1128. https://doi.org/10.1007/s00264-017-3739-0

17. Alvi HM, Monroe EJ, Muriuki M, et al (2016) Latarjet Fixation: A Cadaveric Biomechanical Study Evaluating Cortical and Cannulated Screw Fixation. Orthopaedic Journal of Sports Medicine 4:232596711664353. https://doi.org/10.1177/2325967116643533

18. Schmiddem U, Hawi N, Liodakis E, et al (2019) Monocortical fixation of the coracoid in the Latarjet procedure is significantly weaker than bicortical fixation. Knee Surg Sports Traumatol Arthrosc 27:239-244. https://doi.org/10.1007/s00167018-4837-2

19. Shin JJ, Hamamoto JT, Leroux TS, et al (2017) Biomechanical Analysis of Latarjet Screw Fixation: Comparison of Screw Types and Fixation Methods. Arthroscopy 33:1646-1653. https://doi.org/10.1016/j.arthro.2017.03.030

20. Gendre P, Thélu C-E, d'Ollonne T, et al (2016) Coracoid bone block fixation with cortical buttons: An alternative to screw fixation? Orthopaedics \& Traumatology: Surgery \& Research 102:983-987. https://doi.org/10.1016/j.otsr.2016.06.016

21. Provencher MT, Aman ZS, LaPrade CM, et al (2018) Biomechanical Comparison of Screw Fixation Versus a Cortical Button and Self-tensioning Suture for the Latarjet Procedure. Orthopaedic Journal of Sports Medicine 6:232596711877784. https://doi.org/10.1177/2325967118777842

22. Willemot LB, Wodicka R, Bosworth A, et al (2018) Influence of screw type and length on fixation of anterior glenoid bone grafts. Shoulder Elbow 10:32-39. https://doi.org/10.1177/1758573217704817

23. Hart A, Harvey EJ, Rabiei R, et al (2016) Fixation strength of four headless compression screws. Med Eng Phys 38:1037-1043. https://doi.org/10.1016/j.medengphy.2016.06.025 
24. Garcia JC, do Amaral FM, Belchior RJ, et al (2019) Comparative Systematic Review of Fixation Methods of the Coracoid and Conjoined Tendon in the Anterior Glenoid to Treat Anterior Shoulder Instability. Orthop J Sports Med 7:2325967118820539. https://doi.org/10.1177/2325967118820539

25. Weppe F, Magnussen RA, Lustig S, et al (2011) A biomechanical evaluation of bicortical metal screw fixation versus absorbable interference screw fixation after coracoid transfer for anterior shoulder instability. Arthroscopy 27:1358-1363. https://doi.org/10.1016/j.arthro.2011.03.074

26. Hovelius L, Sandström B, Olofsson A, et al (2012) The effect of capsular repair, bone block healing, and position on the results of the Bristow-Latarjet procedure (study III): long-term follow-up in 319 shoulders. J Shoulder Elbow Surg 21:647660. https://doi.org/10.1016/j.jse.2011.03.020

27. Einhorn TA (2005) The science of fracture healing. J Orthop Trauma 19:S4-6

28. Claes L, Augat P, Suger G, Wilke HJ (1997) Influence of size and stability of the osteotomy gap on the success of fracture healing. J Orthop Res 15:577-584. https://doi.org/10.1002/jor.1100150414

29. Kephart CJ, Abdulian MH, McGarry MH, et al (2014) Biomechanical analysis of the modified Bristow procedure for anterior shoulder instability: is the bone block necessary? J Shoulder Elbow Surg 23:1792-1799. https://doi.org/10.1016/j.jse.2014.03.003

30. Westerhoff P, Graichen F, Bender A, et al (2009) In vivo measurement of shoulder joint loads during activities of daily living. Journal of Biomechanics 42:1840-1849. https://doi.org/10.1016/j.jbiomech.2009.05.035

31. Steeves M, Stone C, Mogaard J, Byrne S (2005) How pilot-hole size affects bonescrew pullout strength in human cadaveric cancellous bone. Can J Surg 48:207-212 


\section{VII - ANNEXES}

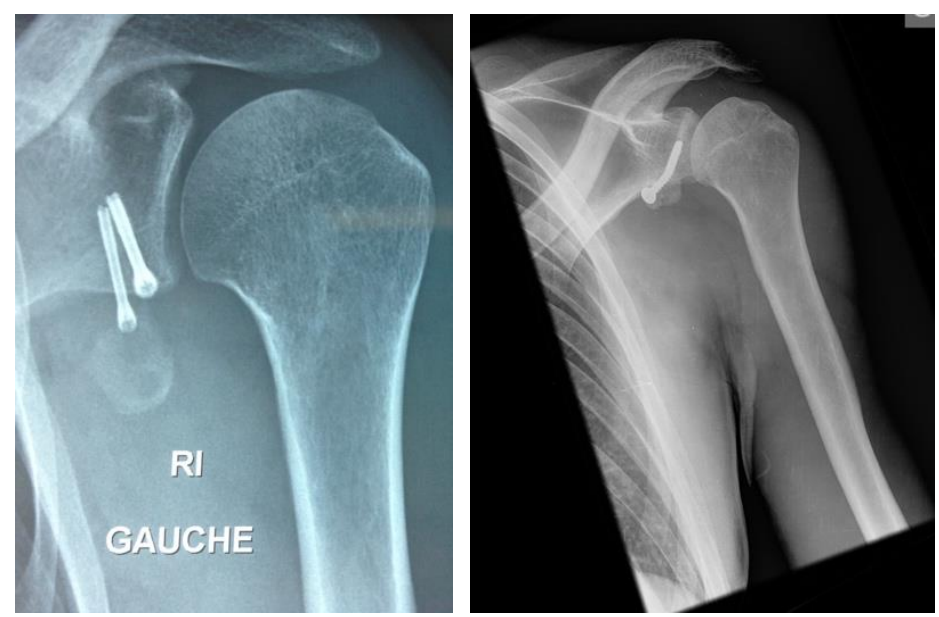

Fig. 1: Examples of Latarjet procedures failure
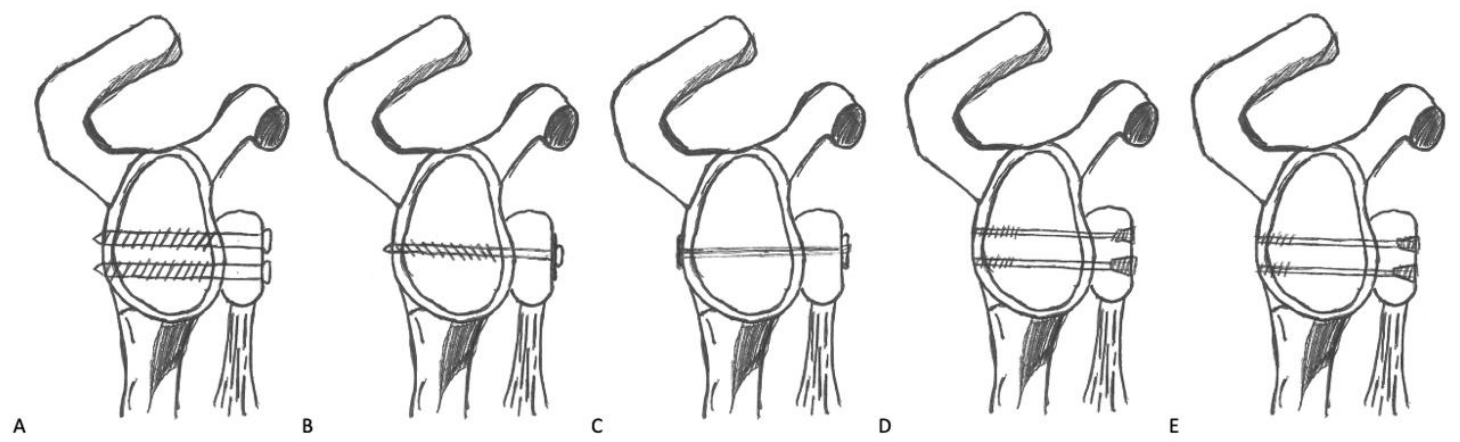

Fig. 2: Lateral view of right scapula after coracoid bone-block fixation. Fixation devices: $A=2$ malleolar screws, $B=$ malleolar screw with washer, $C=$ endobutton, $D=3 \mathrm{~mm}+4 \mathrm{~mm}$ self-compressive screws, $E=2 \times 3.5 \mathrm{~mm}$ self-compressive screws 

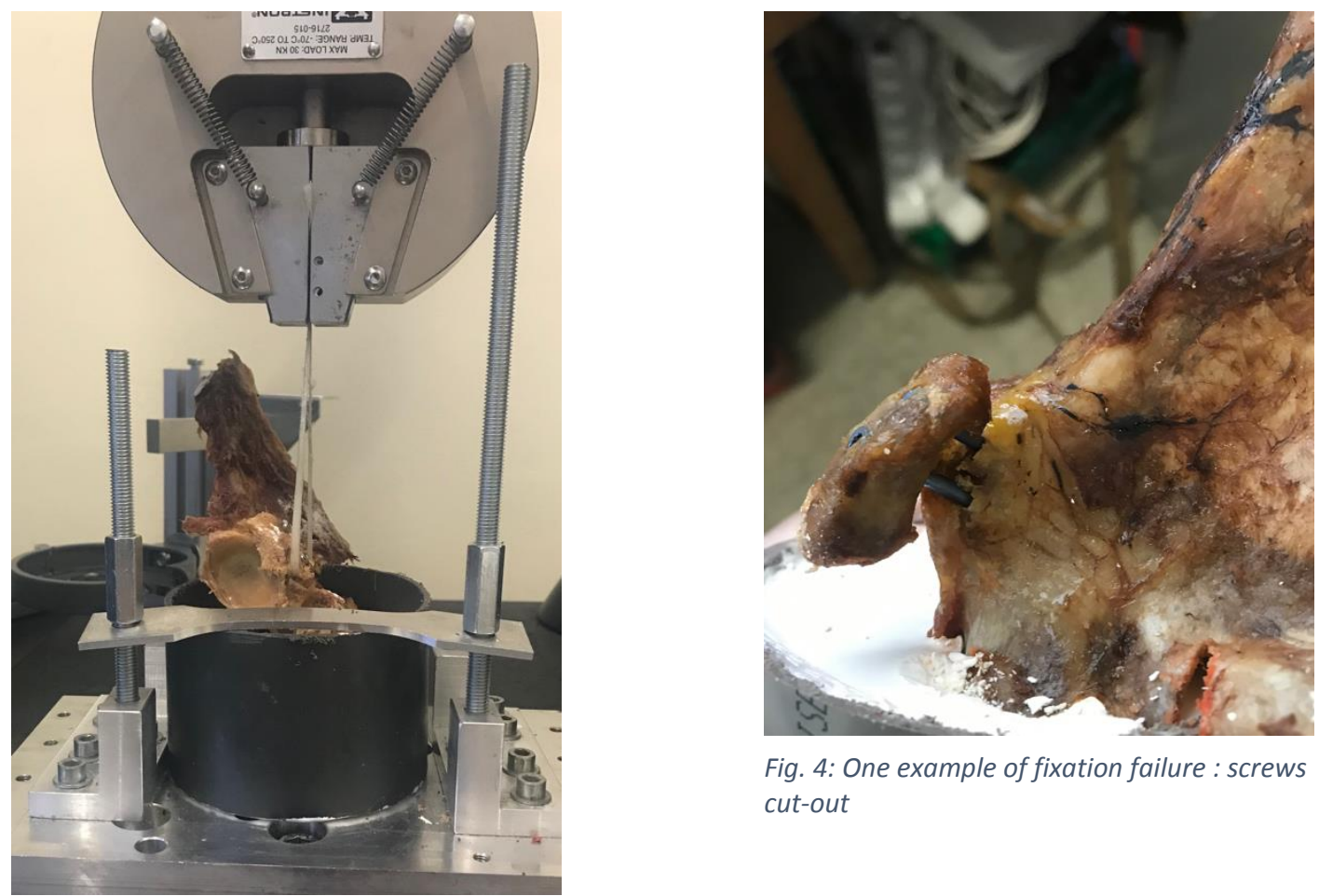

Fig. 4: One example of fixation failure : screws cut-out

Fig.3: Positioning of the model before increasing tension test

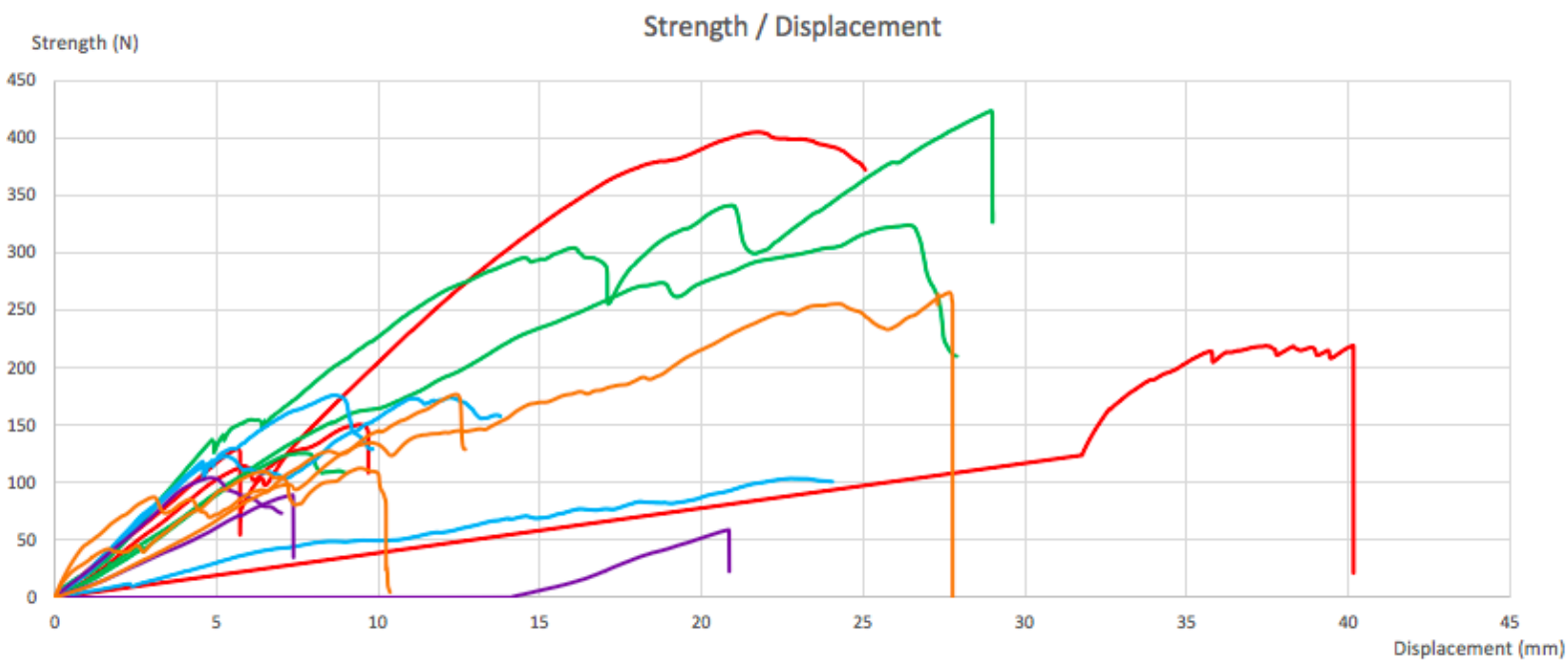

Fig. 5: Strength/Displacement curves.

- Red : $2 * 4.5 \mathrm{~mm}$ malleolar screws

- Purple : $4.5 \mathrm{~mm}$ malleolar screw + washer

- Blue : $2 * 3.5$ self-compressive cannulated screws

- Green : $4 m m+3 m m$ self-compressive cannulated screws

- Orange : Endobutton 


\begin{tabular}{|c|c|c|c|c|c|c|}
\hline & \multicolumn{6}{|c|}{ Main judgement criterion (Strength, in N) } \\
\hline & $\mathrm{N}$ & Mean (SD) & Median (Q25-75) & Min & Max & $\mathrm{P}^{*}$ \\
\hline All samples & 15 & $193(112)$ & $170[108 ; 242]$ & 55.0 & 424 & $N / A$ \\
\hline Endobutton & 3 & $184( \pm 76.8)$ & $176[144-220]$ & 112 & 265 & 0.73 \\
\hline Single screw + washer & 3 & $86.0( \pm 27.1)$ & $98.0[76.5-102]$ & 55.0 & 105 & $<0.01$ \\
\hline $3 \mathrm{~mm}$ screw $+4 \mathrm{~mm}$ screw & 3 & $288( \pm 151)$ & $314[220-369]$ & 125 & 424 & 0.18 \\
\hline $2 * 3.5 \mathrm{~mm}$ screws & 3 & $148( \pm 39.3)$ & $170[136-171]$ & 103 & 172 & 0.63 \\
\hline \multirow[t]{3}{*}{ 2* malleolar screws } & 3 & $257( \pm 129)$ & $220[185-310]$ & 150 & 400 & 0.29 \\
\hline & \multicolumn{6}{|c|}{ Secondary judgement criterion (Stiffness, in N.mm ${ }^{-1}$ ) } \\
\hline & $\mathrm{N}$ & Mean (SD) & Median (Q25-75) & Min & Max & $\mathrm{P}^{*}$ \\
\hline All samples & 15 & $14.6(4.77)$ & $16.2[11.9 ; 17.8]$ & 4.24 & 22.6 & $N / A$ \\
\hline Endobutton & 3 & $11.6( \pm 1.44)$ & $11.6[10.9-12.3]$ & 10.1 & 13.0 & 0.18 \\
\hline Single screw + washer & 3 & $14.9( \pm 6.94)$ & $12.8[11.0-17.7]$ & 9.23 & 22.6 & 0.95 \\
\hline $3 m m$ screw $+4 m m$ screw & 3 & $15.9( \pm 3.22)$ & $17.4[14.8-17.7]$ & 12.2 & 18.1 & 0.73 \\
\hline $2 * 3.5 \mathrm{~mm}$ screws & 3 & $12.7( \pm 7.36)$ & $16.4[10.3-17.0]$ & 4.24 & 17.5 & 0.73 \\
\hline $2^{*}$ malleolar screws & 3 & $18.2( \pm 1.99)$ & $18.3[17.2-19.2]$ & 16.2 & 20.1 & 0,14 \\
\hline
\end{tabular}

Table 1: Tests results and statistical analysis 


\begin{tabular}{|c|c|c|c|c|c|c|}
\hline & \multicolumn{6}{|c|}{ Main judgement criterion (Strength, in $\mathbf{N}$ ) } \\
\hline & $\mathrm{N}$ & Mean (SD) & Median (Q25-75) & Min & Max & $P^{*}$ \\
\hline All samples & 15 & $193(112)$ & $170[108 ; 242]$ & 55.0 & 424 & $N / A$ \\
\hline Endobutton & 3 & $184( \pm 76.8)$ & $176[144-220]$ & 112 & 265 & 0.73 \\
\hline Single screw + washer & 3 & $86.0( \pm 27.1)$ & $98.0[76.5-102]$ & 55.0 & 105 & $<0.01$ \\
\hline $3 m m$ screw $+4 m m$ screw & 3 & $288( \pm 151)$ & $314[220-369]$ & 125 & 424 & 0.18 \\
\hline $2 * 3.5 \mathrm{~mm}$ screws & 3 & $148( \pm 39.3)$ & $170[136-171]$ & 103 & 172 & 0.63 \\
\hline \multirow[t]{3}{*}{ 2* malleolar screws } & 3 & $257( \pm 129)$ & $220[185-310]$ & 150 & 400 & 0.29 \\
\hline & \multicolumn{6}{|c|}{ Secondary judgement criterion (Stiffness, in N. mm ${ }^{-1}$ ) } \\
\hline & $\mathrm{N}$ & Mean (SD) & Median (Q25-75) & Min & Max & $\mathrm{P}^{*}$ \\
\hline All samples & 15 & $14.6(4.77)$ & $16.2[11.9 ; 17.8]$ & 4.24 & 22.6 & $N / A$ \\
\hline Endobutton & 3 & $11.6( \pm 1.44)$ & $11.6[10.9-12.3]$ & 10.1 & 13.0 & 0.18 \\
\hline Single screw + washer & 3 & $14.9( \pm 6.94)$ & $12.8[11.0-17.7]$ & 9.23 & 22.6 & 0.95 \\
\hline $3 m m$ screw $+4 m m$ screw & 3 & $15.9( \pm 3.22)$ & $17.4[14.8-17.7]$ & 12.2 & 18.1 & 0.73 \\
\hline $2 * 3.5 \mathrm{~mm}$ screws & 3 & $12.7( \pm 7.36)$ & $16.4[10.3-17.0]$ & 4.24 & 17.5 & 0.73 \\
\hline 2* malleolar screws & 3 & $18.2( \pm 1.99)$ & 18.3 [17.2 - 19.2] & 16.2 & 20.1 & 0,14 \\
\hline
\end{tabular}



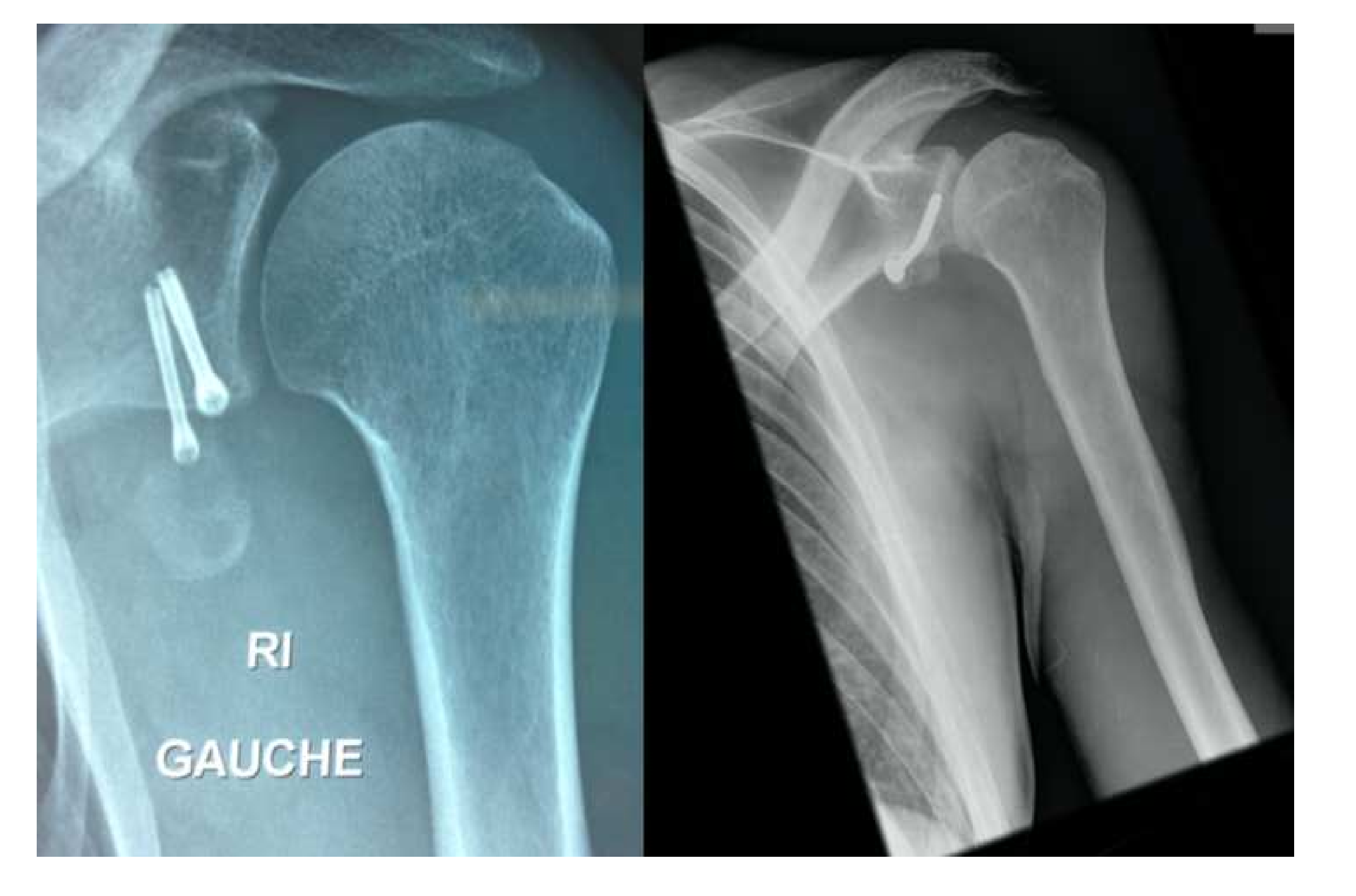

.

. 


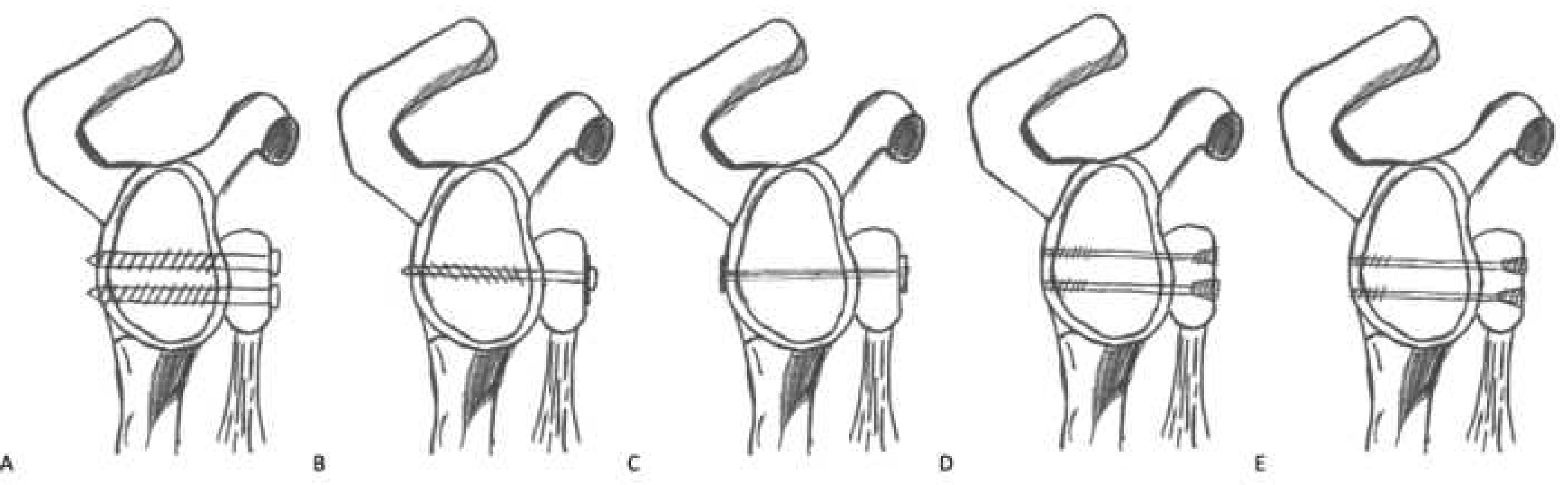




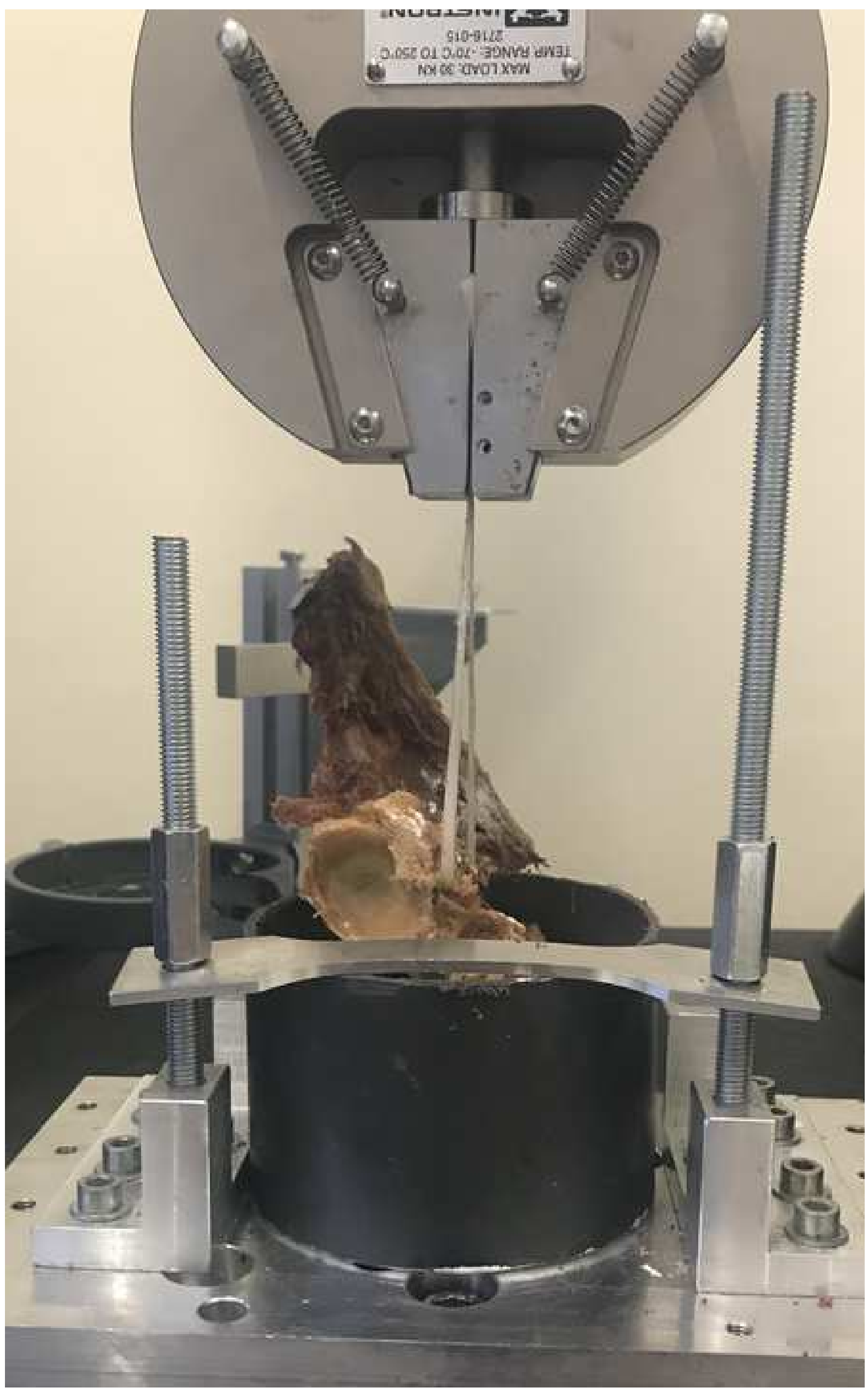




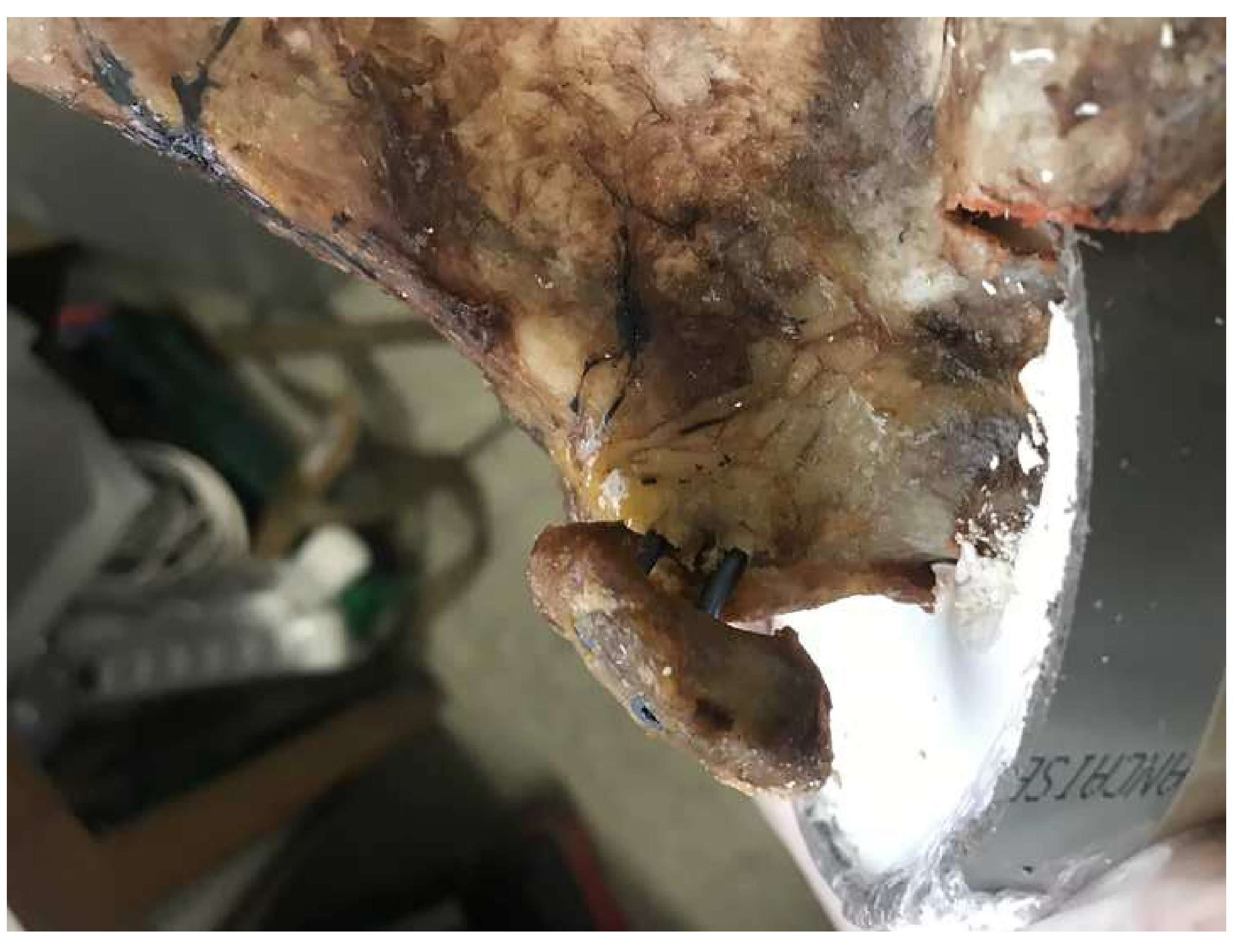

Click here to access/download;Figure;Fig4.JPG $\underline{\underline{ \pm}}$ 


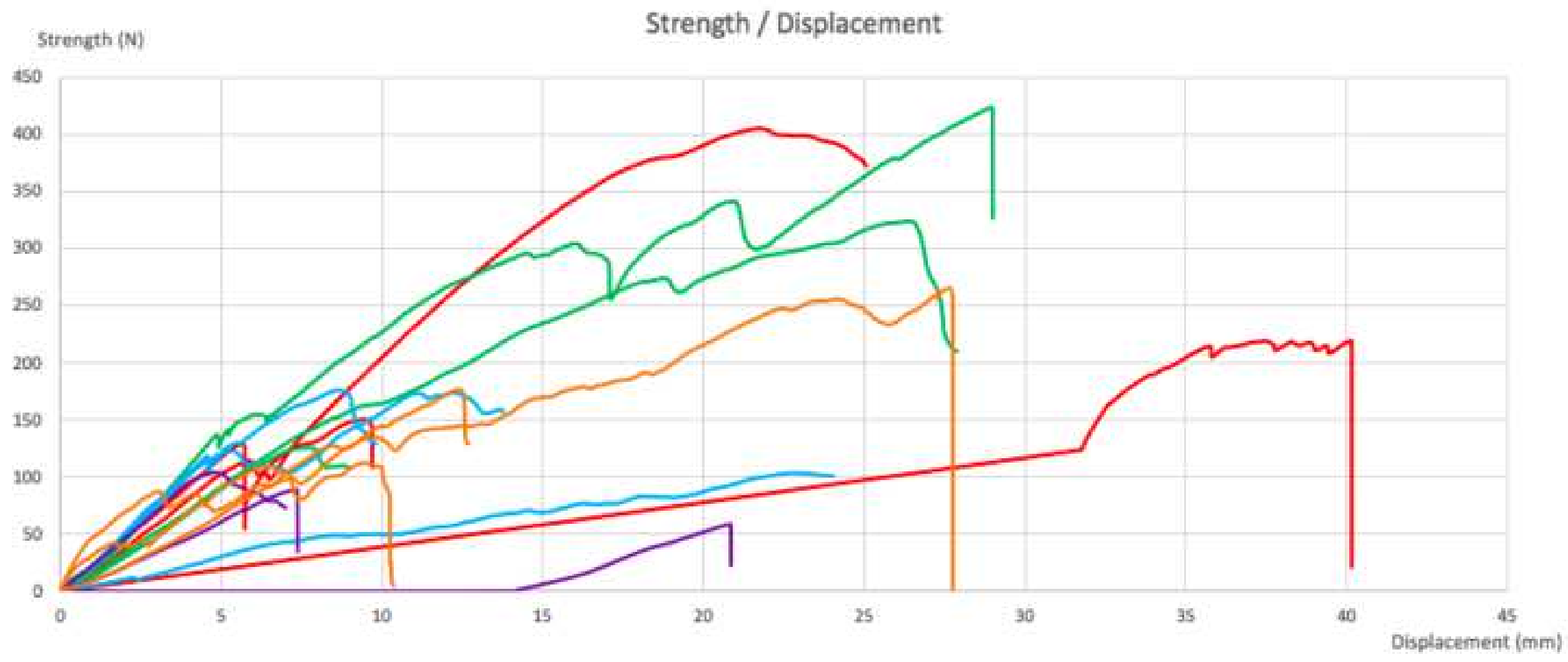

